\title{
O PERFIL PROFISSIONAL DOCENTE NO BRASIL: PROSPECTOS E PROGNÓSTICOS
}

\author{
Resenha do livro: \\ FLEURI, Reinaldo Matias. Perfil Profissional Docente no Brasil: metodologias e \\ categorias de pesquisas. Brasília: INEP-MEC, 2015. Série Documental - Relatos de \\ Pesquisa 40.
}

\section{Resenhado por: Rodrigo Tarcha Amaral de Souza ${ }^{1}$}

O presente relatório, organizado como série documental, trata da descrição, análise e problematização dos resultados de pesquisa de cinco agências de fomento, estudo e implementação de ações educacionais, que por sua vez, com metodologias, critérios e propósitos distintos, apresentam suas pesquisas relacionadas ao perfil profissional docente no Brasil e no mundo. O Autor, Reinaldo Matias Fleuri, renomado pesquisador brasileiro, coordenou este trabalho de pesquisa, podendo ser concebido como um diagnóstico do perfil profissional docente para implementação de políticas educacionais posteriores, que vislumbrem um melhor enquadramento deste profissional na sociedade.

O relatório apresenta suficiente material empírico para descrição e é elaborado em linguagem adaptada a leitores especializados e também àqueles que, por motivos diversos, tenham acesso a sua leitura. Estruturou-se em três capítulos e ainda as considerações iniciais e finais. Descreve no primeiro capítulo sobre os Estudos a respeito do perfil docente no Brasil entre 2004 e 2014. No segundo capítulo, analisa-os, guiado por categorias constitutivas do que afirma ser os traços do perfil profissional docente, embora mais no âmbito das semelhanças do que suas distinções. Expõe no capítulo três, recomendações para a reformulação das categorias constitutivas do perfil profissional docente, como pano de fundo para uma discussão mais completa.

Em suas considerações iniciais, apresenta os limites deste relatório, tendo como objetivo a comparação das pesquisas recentes realizadas sobre o perfil profissional dos docentes de educação básica no Brasil e no mundo. Percebe-se, porém, que para além da possibilidade deste relatório ser efetivamente um instrumento para futuras formulações de metodologias e de modelos de pesquisa sobre o perfil profissional docente, pode, contraditoriamente, enfraquecer o debate sobre o perfil deste profissional, uma vez que seus resultados estão ancorados em instituições educacionais renomadas, podendo ser assumidos como inequívocos.

A descrição realizada no capítulo um, considerou as pesquisas e estudos do Censo da Educação Básica, base do Estudo exploratório sobre o professor brasileiro, do Inep (2009); O perfil dos professores brasileiros: o que fazem, o que pensam, o que almejam, da Unesco (2004); o "survey" do Grupo de Estudos sobre Política Educacional e Trabalho Docente da Universidade Federal de Minas Gerais (Gestrado) (2010) e o estudo do Instituto Paulo Montenegro (IPM) - , comparados com os resultados da pesquisa Internacional sobre Ensino e Aprendizagem (Teaching and Learning International Survey (TALIS), realizada em 2013 com a participação do Brasil. São pesquisas que revelam uma macroestrutura, considerando dados quantificáveis e verificáveis, podendo ser cruzados e analisados. Cada uma das seguintes pesquisas apresentou um quadro de amostragem diferente, próprio de seus interesses e lugares de abordagem. Cabe pensar nas 
particularidades existentes não consideradas em pesquisas quantificáveis, o que permite questionar os conceitos oriundos exclusivamente destas pesquisas.

A pesquisa TALIS foi realizada pela (OECD) Organização para Cooperação e Desenvolvimento Econômico, como parte do Programa de Indicadores de Sistemas Educacionais. Seu fornecimento de indicadores internacionais da Educação, favorece a realização da análise e comparação dos países que enfrentam desafios semelhantes, permitindo a comparabilidade internacional e a nacional. Realizada em 30 países, em 2013, foram pesquisadas 380 escolas no Brasil, com entrevistas de seus diretores mediante questionários, e 5.835 professores, estes definidos pela TALIS como "profissionais", cuja principal atividade na escola é o ensino. Focalizou, prioritariamente, a educação fundamental em seus anos finais, equivalente no Brasil do $6^{\circ}$ ao $9^{\mathrm{a}}$ ano. A Pesquisa TALIS resume suas conclusões, levando em conta eixos norteadores encontrados nos questionários. Apresenta-os de maneira didática e os universaliza para todos os educadores. Tenha-se como exemplo a constatação de que, num contexto internacional, os professores trabalham em média 38 horas semanais. Cabe a reflexão sobre os riscos de universalizações em que inferem prerrogativas jurídicas e trabalhistas para cada país pesquisado, sabendo-se que nem sempre as universalizações de dados representam a realidade local.

O Censo Escolar da Educação Básica, pesquisa realizada pelo Instituto Nacional de Estudos e Pesquisas Educacionais Anísio Teixeira (Inep), é considerado o mais abrangente levantamento estatístico educacional brasileiro, coletando dados sobre estabelecimentos de ensino, turmas, alunos, profissionais escolares em sala de aula, movimento e rendimento escolar, com o objetivo de traçar um panorama da educação básica. Sua principal fonte de informações é o diretor da escola e utiliza a definição de "função docente" para focalizar as diferentes atribuições de cada professor.

A pesquisa da Unesco (2004) discute o papel da escola e do professor na sociedade contemporânea, as demandas e as estratégias de formação inicial e continuada dos docentes, o contexto social e político que envolve o cotidiano e o trabalho educacional deles. Sua pesquisa reconhece a importância do "fator docente", no processo de aprendizagem na escola, inferência que corresponde a sua finalidade de colaboradora na formação de professores e outros arranjos educacionais. A pesquisa se deu por meio de questionários autoaplicáveis a cinco mil professores brasileiros que atuavam em 2002 no ensino fundamental e médio das redes pública e privada de ensino. Torna-se desafiador para esta agência de fomento e pesquisa educacional, ser coerente com seus propósitos, quando ressente de necessárias parcerias com o Banco Mundial, instituições privadas e afins, que apontam para lógicas neoliberais. Neste contexto, faz-se necessário questionar, não somente a legitimidade dos resultados de sua pesquisa, mas também o rigor metodológico e seu respectivo viés.

O Grupo de Estudo sobre Política Educacional e Trabalho Docente (GESTRADO) da Universidade Federal de Minas Gerais (UFMG), procurou traçar o perfil socioeconômico e cultural dos docentes em exercício de postos, cargos e funções derivados de novas exigências e atribuições. Neste "survey" (2010), adota o conceito de "sujeito docente", focalizando os profissionais que desenvolvem algum tipo de atividade de ensino ou docência. Realizou entrevistas com 8.895 sujeitos docentes de educação básica de sete estados brasileiros. Trata-se, por assim dizer, de uma pesquisa qualitativa e quantitativa, por considerar na metodologia de análise, a subjetividade dos sujeitos presentes nas bases da educação, de maneira complementar aos dados quantificáveis.

A pesquisa "Ser professor: Uma pesquisa sobre o que pensa o docente das principais capitais brasileiras" do Instituto Paulo Montenegro (IPM) 2010, é parte de uma 
coletânea de pesquisas educacionais da Fundação Victor Civita (FVC). A pesquisa em questão visou entender o universo do educador brasileiro. Para tanto, entrevistou quinze professores da educação infantil, ensino fundamental e médio da rede pública, residentes nas principais capitais das Regiões Norte, Nordeste, Sudeste, Sul e Centro Oeste. Não apontou detalhes ampliados, já que teve amostragem reduzida.

O capítulo dois deste relatório tece uma análise comparativa dos estudos sobre o perfil profissional dos docentes. Apresenta a diferenciação das metodologias e realiza o cruzamento de alguns eixos de análise, embora não aprofunde as motivações que guiaram os critérios metodológicos de cada estudo. Compara as concepções dos sujeitos das pesquisas, aqui, ressaltado em parágrafos anteriores. Analisa e compara a abrangência geográfica das pesquisas; reflete sobre a significação do trabalho docente, as categorias constitutivas do perfil profissional docente, bem como sua respectiva abrangência enquanto perfil pessoal sociodemográfico e profissional. No final deste capítulo, apresenta suas considerações sobre os traços do perfil profissional docente em âmbito de questões emergenciais, considerando, sobremaneira, o discurso humanitário na revisão da concepção epistemológica, metodológica e de políticas educacionais brasileiras. Percebese, todavia, que, numa ordem prática, de maneira sutil, o autor destaca dados das pesquisas que apresentam viés gerencialista e, portanto, neoliberal, tornando frágeis suas considerações.

No terceiro capítulo, o autor recupera a estrutura analisada por meio de comparações teórico-metodológicas, inferindo sobre a relativa consistência das categorias constitutivas do perfil profissional docente, podendo ser ampliadas e reelaboradas, de modo a possibilitarem a formulação de itens e de indicadores de pesquisa consistentes à complexidade dos contextos socioculturais brasileiros contemporâneos.

Em suas considerações finais, o autor reconhece os significativos avanços teóricos no debate sobre o perfil profissional docente, bem como o seu desenvolvimento metodológico nos processos de pesquisa, embora sinalize a necessidade de formulação de uma metodologia de pesquisa para a atualização dos docentes no Brasil. Ao final, o autor manifesta o anseio de que tal estudo possa subsidiar projetos de atualização do perfil docente no Brasil.

Em suma, o relatório é profícuo de dados empíricos, mas frágil no rigor metodológico quanto aos procedimentos de análise dos dados, havendo ainda, possíveis parcialidades nas ênfases das informações. Próprio das pesquisas de macroestrutura, sua universalização de informações representa uma corrosão das subjetividades, além de não corresponder completamente à realidade da educação. A intencionalidade em diagnosticar o perfil profissional docente para atendê-lo melhor, pode inversamente, colonizá-lo, movido por ambições não humanitárias, mas contrariamente, neoliberais. A análise deste relatório é importante enquanto publicação governamental, tendo, porém, atenção aos sutis nuances epistemológicos.

\footnotetext{
${ }^{1}$ Doutorando do Programa de Pós-Graduação em Educação - Universidade Metodista de Piracicaba UNIMEP. Professor do Centro Universitário Salesiano de São Paulo - UNISAL, unidade São José/Campinas, SP. Integrante do Grupo de Pesquisa Antropologia Teológica. E-mail: ir.tarcharo@ hotmail.com
} 